DOI: $10.20472 /$ IAC.2017.030.019

\author{
JINHYUN KIM \\ College of Nursing, Seoul National University, Korea, Republic of \\ EUNHEE LEE \\ Division of Nursing, Hallym University, Korea, Republic of \\ KYOUNGA LEE \\ College of Nursing, Seoul National University, Korea, Republic of \\ YEONHEE KIM \\ Nursing Department, Asan Medical Center, Korea, Republic of \\ SUNHEE LEE \\ Children's Nursing Team, Asan Medical Center, Korea, Republic of \\ JIHEY KIM \\ GI outpatient Department, Asan Medical Center, Korea, Republic of \\ KYEONGYEON OH \\ GI outpatient Department, Asan Medical Center, Korea, Republic of \\ KYEONGOK HEO \\ Urology Department, Asan Medical Center, Korea, Republic of \\ HYUNAH CHOI \\ GY inpatient Department, Asan Medical Center, Korea, Republic of \\ , Korea, Republic of
}

\title{
DEVELOPMENT OF OPTIMAL NURSING WORKFORCE MODEL AND ITS APPLICATION TO OUTPATIENTS IN A TERTIARY HOSPITAL
}

\begin{abstract}
:
The purpose of this study is to develop an optimal allocation model of nursing workforce and apply it to outpatients at a tertiary hospital in Korea. A workload model that consists of average number of patients per day and nursing time per patient was used to estimate the optimal number of nursing workforce in each clinical department, considering the annual off days per nursing staff. The nursing time was classified into three stages(reception-treatment-consulting) and the data were collected by one-to-one observation for three years. It was analyzed by three scenarios: scenario 1 considered actual days spent on vacation and holiday, scenario 2 reflected all holidays and annual leaves under labor act, and scenario 3 included only mandatory holidays and off days. The average number of patients per day varied from 29 to 846 according to clinical department, and required nursing time per patient was from 5.1 to 14.2 minutes. The actual nursing staffs per clinical department were 7.6 persons. The optimal nursing workforce was $7.1,6.4$, and 6.0 persons, respectively in the scenario 1 , 2 , and 3. In scenario 1, it was analyzed that -3.6 to 7.9 additional nursing staffs should be employed and an average of 0.5 staffs can be reduced. In scenario 2, it was analyzed that -2.9 to 8.7 (average 1.3) additional nursing staffs need to be employed. Lastly, scenario 3 estimated that -2.5 to 9.2
\end{abstract}


(average 1.7) additional nursing staffs need to be employed. However, this study estimated an optimal nursing workforce to a decimal point, while the number of nurses employed in real world is a positive integer. With nursing manpower allocation rounded to the nearest decimal, nurse staffing condition and patient outcomes could be improved. Therefore, it is recommended to consider an integer model of nurse staffing level in the further detailed studies.

* This study was supported by National Research Foundation of Korea.

\section{Keywords:}

Nursing workforce, Nurse staffing model, Workload 